\title{
Major air pollutants and risk of COPD exacerbations: a systematic review and meta-analysis
}

\author{
Jinhui $\mathrm{Li}^{1,2}$ \\ Shengzhi Sun 1,2 \\ Robert Tang ${ }^{1,2}$ \\ Hong Qiu ${ }^{2}$ \\ Qingyuan Huang ${ }^{3}$ \\ Tonya G Mason ${ }^{2}$ \\ Linwei Tian ${ }^{1,2}$
}

'Shenzhen Institute of Research and Innovation, Nanshan, The University of Hong Kong, Shenzhen, People's Republic of China; ${ }^{2}$ School of Public Health, The University of Hong Kong, Pok Fu Lam, Hong Kong Special Administrative Region; ${ }^{3}$ Department of Thoracic Surgery, Shanghai Chest Hospital, Shanghai Jiao Tong University, Minhang, Shanghai, People's Republic of China
Correspondence: Linwei Tian

Shenzhen Institute of Research and Innovation, School of Public Health, The University of Hong Kong, 7 Sassoon Road, Pok Fu Lam, Hong Kong Special Administrative Region, People's Republic of China

Tel +852 39l7635I

Email linweit@hku.hk
This article was published in the following Dove Press journal:

International Journal of COPD

12 December 2016

Number of times this article has been viewed

Background: Short-term exposure to major air pollutants $\left(\mathrm{O}_{3}, \mathrm{CO}, \mathrm{NO}_{2}, \mathrm{SO}_{2}, \mathrm{PM}_{10}\right.$, and $\left.\mathrm{PM}_{2.5}\right)$ has been associated with respiratory risk. However, evidence on the risk of chronic obstructive pulmonary disease (COPD) exacerbations is still limited. The present study aimed at evaluating the associations between short-term exposure to major air pollutants and the risk of COPD exacerbations.

Methods: After a systematic search up until March 30, 2016, in both English and Chinese electronic databases such as PubMed, EMBASE, and CNKI, the pooled relative risks and $95 \%$ confidence intervals were estimated by using the random-effects model. In addition, the population-attributable fractions (PAFs) were also calculated, and a subgroup analysis was conducted. Heterogeneity was assessed by $P^{2}$.

Results: In total, 59 studies were included. In the single-pollutant model, the risks of COPD were calculated by each $10 \mu \mathrm{g} / \mathrm{m}^{3}$ increase in pollutant concentrations, with the exception of CO $\left(100 \mu \mathrm{g} / \mathrm{m}^{3}\right)$. There was a significant association between short-term exposure and COPD exacerbation risk for all the gaseous and particulate pollutants. The associations were strongest at lag0 and lag3 for gaseous and particulate air pollutants, respectively. The subgroup analysis not only further confirmed the overall adverse effects but also reduced the heterogeneities obviously. When $100 \%$ exposure was assumed, PAFs ranged from $0.60 \%$ to $4.31 \%$, depending on the pollutants. The adverse health effects of $\mathrm{SO}_{2}$ and $\mathrm{NO}_{2}$ exposure were more significant in low-/middle-income countries than in high-income countries: $\mathrm{SO}_{2}$, relative risk: 1.012 (95\% confidence interval: 1.001 , 1.023); and $\mathrm{NO}_{2}$, relative risk: 1.019 (95\% confidence interval: 1.014, 1.024).

Conclusion: Short-term exposure to air pollutants increases the burden of risk of COPD acute exacerbations significantly. Controlling ambient air pollution would provide benefits to COPD patients.

Keywords: COPD exacerbations, air pollution, meta-analysis, acute exposure

\section{Introduction}

Air pollution has been a serious environmental problem and a major concern for public health worldwide. It continues to be a major environmental health risk, particularly in developing countries where the motor vehicle traffic and industrialization increase quickly. ${ }^{1}$ The respiratory system (tract and lung) is vulnerable to air pollutants, including ozone $\left(\mathrm{O}_{3}\right)$, carbon monoxide $(\mathrm{CO})$, nitrogen dioxide $\left(\mathrm{NO}_{2}\right)$, sulfur dioxide $\left(\mathrm{SO}_{2}\right)$, and particulate matters $\left(\mathrm{PM}_{2.5}, \mathrm{PM}_{10}\right)$. In the course of pulmonary ventilation and gas exchange, these pollutants could induce oxidative stress and inflammation, resulting in airway injury and dysfunction. ${ }^{2}$ 
Chronic obstructive pulmonary disease (COPD) is the third leading cause of mortality worldwide. It is estimated that the number of COPD patients has reached a record of 7.3 billion in $2015 .{ }^{3}$ Factors that cause exacerbation of COPD include clinical and medical care status, natural and social environmental changes, and lifestyles. ${ }^{4}$ The exacerbation symptoms mainly include the increase in dyspnea, sputum production, or purulence and then the emergency hospitalization or even mortality. ${ }^{5}$ In some parts of the world, acute exacerbation of COPD accounts for 1 of 10 leading causes of hospital admission, which bring formidable challenges to the world health and socioeconomic systems. ${ }^{6}$

The acute effects of air pollution exposure on COPD exacerbations have been investigated by several studies, but the results still remain inconsistent. Some reported that air pollutions significantly increased the risk of exacerbation or mortality, ${ }^{7,8}$ whereas others found no associations ${ }^{9,10}$ or relationships only for selected pollutants. ${ }^{11,12}$ Moreover, several recent investigations were conducted in certain regions and were just focused on particulate air pollutions.

To the authors' knowledge no comprehensive and systematic meta-analysis has yet been published to investigate the association of acute COPD exacerbations with short-term air pollutants exposure. Therefore, the aim of the present study was to systematically review the evidence evaluating the acute risk for COPD patients when exposed to short-term air pollution.

\section{Methods}

\section{Search strategy}

Systematic searches were performed to identify the studies on the associations between major air pollutants and COPD exacerbation. The comprehensive online electronic databases included both English and Chinese databases through March 30, 2016: Web of Science (1956-2016), Ovid MEDLINE and Ovid MEDLINE in the process (1946-2016), EMBASE (1974-2005), Environmental Sciences and Pollution Management Index, CINAHL, Google Scholar and Cochrane database (2005-2016), and CNKI. Moreover, references were checked for additional publication details. Supplementary material S1 contains the search strategy. Duration of up to 7 days (lag6) was selected. If the included papers had insufficient data, the corresponding authors were contacted by email, and the papers were excluded only if there was no response from the corresponding authors.

\section{Selection of studies}

The inclusion criteria (Supplementary material S2) were as follows: 1) a case-crossover or time-series study; and
2) evaluation of the short-term effects of air pollutants on the acute risk of COPD with recorded end points. Figure 1 summarizes the selection procedures in a flow chart.

One reviewer (JH Li) performed all the initial evaluations of titles and abstracts. The other investigator (QY Huang) randomly assessed 500 samples, and no controversy was found. Full text of these potential studies was then screened to determine the eligibility by these two authors independently. During full-text selection, conflicts were settled by consensus or adjusted by a third reviewer (SZ Sun).

\section{Quality score assessment}

This meta-analysis was conducted according to the items of PRISMA and MOOSE. ${ }^{13,14}$ Although Mustafic et al suggested to evaluate the quality of time-series or case-crossover studies, ${ }^{15}$ there were still no validated scales recommended. ${ }^{16}$ Therefore, a 4-component scoring system (0-1 point for each item) was designed as follows: 1) the quality of air pollution assessment $(<25 \%$ of the values for one specific day were missing); ${ }^{15}$ 2) the validation of COPD exacerbation (the disease was coded according to the International Classification of Diseases, Revision 10, American Thoracic Society or other laboratory/clinical prognosis golden criteria, such as $\mathrm{FEV}_{1} / \mathrm{FVC}<0.7$ for lung function); 3) the adjustment for confounders (temperature, seasonality, long-term trend, etc were adjusted); and 4) the generalizability of the outcomes (providing clear defined hospitals or health maintenance organizations). ${ }^{17}$

\section{Data extraction and statistical synthesis}

The two investigators (JH Li and QY Huang) conducted the data extraction independently, and discordance was resolved by discussing with another researcher (LW Tian). By assuming a linear relationship between air pollution and COPD, the relative risks (RRs) with 95\% confidence interval (CI) for a standardized increment of pollutants' concentrations were pooled as follows: $10 \mu \mathrm{g} / \mathrm{m}^{3}$ for $\mathrm{PM}_{2.5}, \mathrm{PM}_{10}, \mathrm{NO}_{2}, \mathrm{SO}_{2}$, and $\mathrm{O}_{3}$ and $100 \mu \mathrm{g} / \mathrm{m}^{3}$ for $\mathrm{CO}$. These values were frequently used in the previous air-pollution-related studies. ${ }^{18}$ If percentage change with $95 \%$ CI were reported, then it could be transformed to RR with 95\% CI. Besides, if odds ratios were found, they could be considered equivalent to RRs in timeseries or case-crossover studies. ${ }^{19}$ Then, the standardized risk was unified according to the method by Yang et al. ${ }^{17}$

The present study was designed to have short-term exposure because the risk factors varied constantly in this period and could not be promptly confounded by fluctuating and meteorological parameters. ${ }^{20}$ There had been no standard criteria for reporting lag patterns so far, and most studies 


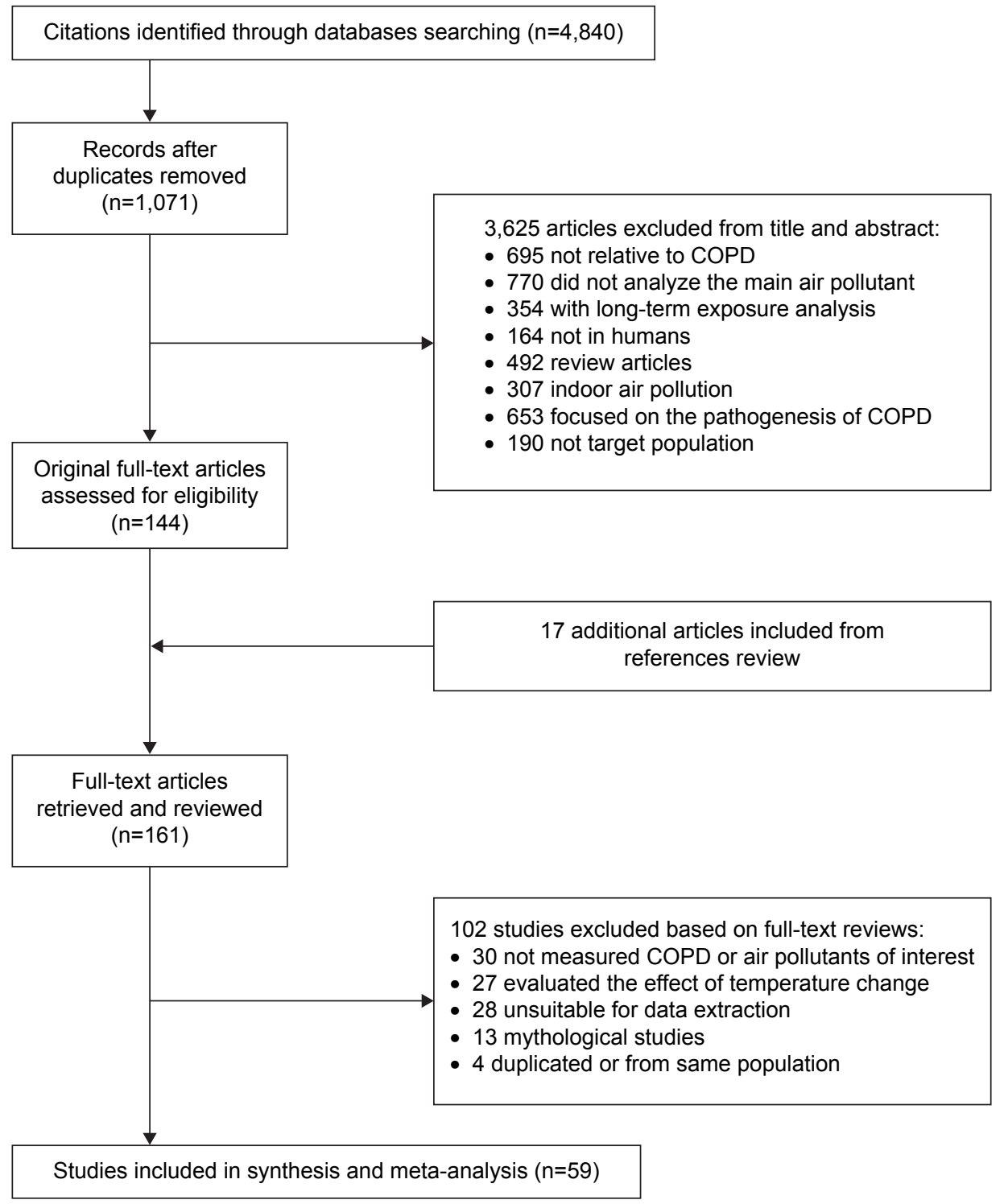

Figure I PRISMA flow chart of identified, included, and excluded studies.

Abbreviation: COPD, chronic obstructive pulmonary disease.

employed single-day lag; therefore, lag selection procedure was based on "priori lag" theory of Atkinson et al. ${ }^{11}$ Briefly, when only one lag estimate was presented, it would be adopted first; if numerous lags were reported, our selection was based on the following algorithms: 1) the most frequently used lag in all the selected studies was under consideration; and 2) compared to the cumulative/distributed lags, single lags were chosen as priorities.

The heterogeneity was assessed by $I^{2}$. When heterogeneity was significant $\left(I^{2}>25 \%\right)$, the random-effects model was applied; otherwise, the fixed-effects model was used. ${ }^{21}$ In order to explore the sources of heterogeneity, subgroup and meta-regression analyses were performed based on study design, population location, age, and outcome category. In order to determine whether the findings could be affected by removing one or two studies, sensitivity analysis was conducted to explore robustness. ${ }^{22}$ If the omission of any study would not affect the overall results, then the outcome of the review can be regarded with a higher degree of certainty. ${ }^{23}$

The population-attributable fractions (PAFs) are reduced proportions of disease hospitalization or mortality in the population when the exposure risk factor was reduced to an expected scenario. First, they were assumed to be $100 \%$ in some industrialized areas according to the recognized method by Dr Mustafic. ${ }^{15}$ Besides, in some light-polluted regions, the prevalence percentages were suggested to be assumed lower, in which case the estimated prevalence values were $80 \%$ and $20 \%$ in the present study. ${ }^{19}$ The equation is as follows: $\left\{\mathrm{PAF}=k^{*}(\mathrm{RR}-1) /\left[k^{*}(\mathrm{RR}-1)+1\right]\right\}$ (where $k$ indicates the air pollution exposure percentages $).{ }^{15}$ 
Publication bias was evaluated by using Begg's funnel plot method and confirmed by Egger's method. ${ }^{24}$ Asymmetry was then corrected through trim and fill method, and an adjusted summary was achieved by using all the original studies together with "filled" data. ${ }^{19}$ Moreover, the pooled effect estimates based on income status of country defined by the gross national income per capita of World Bank were also explored. ${ }^{25}$

The statistical analyses were conducted by using STATA Version 12.1 (STATA/SE, College Station, TX, USA) and R Software (Version 3.1.2). Significance for pooled estimates was defined as two-sided $P<0.05$.

\section{Results}

\section{Literature search and study characteristics}

Figure 1 shows the selection process of the identified 4,840 studies. A total of 59 studies fulfilled all the criteria and were included in the analysis, consisting of 13 case-crossover studies and 46 time-series studies.

Table 1 summarizes the basic characteristics of the included publications. The number of populations ranged from 4,989 to 58 million. All the research studies were published between 1992 and 2015 and were performed in Asia (People's Republic of China, Japan, Korea, and India),

Table I Contextual details of the studies included in the meta analysis

\begin{tabular}{|c|c|c|c|c|c|c|c|c|}
\hline Study (year) & Location & Design & Period & Outcome & Population & Events & Age & Confounders \\
\hline Kloog et $\mathrm{al}^{46}(2014)$ & USA & $\mathrm{CC}$ & $2000-2006$ & $\mathrm{HA}$ & 58.0 million & 0.42 million & $\geq 65 \mathrm{yrs}$ & $A$ \\
\hline Meng et al ${ }^{47}(2013)$ & China & TS & $1996-2008$ & Mortality & 34.0 million & $32.2 /$ day & All & A.B \\
\hline Tellez-Rojo et al ${ }^{48}(2000)$ & Mexico & TS & $1994-1995$ & Both & 0.9 million & 2,294 & $\geq 65$ yrs & A.B.C.D.E.F \\
\hline Wordley et a $\mathrm{a}^{49}$ (1997) & UK & TS & $1992-1994$ & Both & I million & $\begin{array}{l}\text { HA } 3.2 / \text { day, } \\
\text { M 2/day }\end{array}$ & All & A.B \\
\hline Neuberger et $\mathrm{al}^{7}$ (2007) & Austria & TS & $1972-1983$ & Mortality & I.6 million & 2,878 & $\geq 65$ yrs & A.B.E.G.H \\
\hline Yorifuji et al ${ }^{50}(2014)$ & Japan & $\mathrm{CC}$ & $2006-2010$ & $\mathrm{HA}$ & 6,925 & 761 & $\geq 65 \mathrm{yrs}$ & A.B.H \\
\hline Schikowski et al ${ }^{51}(2014)$ & Taiwan & CC & $2006-2010$ & $\mathrm{HA}$ & I.5 million & 7.7/day & All & A.B.C.E.I \\
\hline Tao et $\mathrm{al}^{52}(20 \mathrm{|})$ & China & TS & $200 I-2005$ & $\mathrm{HA}$ & NA & $2.0 /$ day & All & A.B.C.G.F \\
\hline Moolgavkar et al ${ }^{53}$ (1997) & Europe & TS & $|986-199|$ & $\mathrm{HA}$ & NA & $2.6 /$ day & All & A.C.F.I \\
\hline Hinwood et al $\left.\right|^{54}(2006)$ & Australia & $\mathrm{CC}$ & $1992-1998$ & $\mathrm{HA}$ & 1.2 million & 3.3/day & All & A.B.C.D \\
\hline Milutinovic et al55 (2009) & Serbia & TS & $2002-2003$ & $\mathrm{HA}$ & 0.17 million & $12.5 /$ day & All & A.B.G.J.K.L.M \\
\hline Arbex et al ${ }^{56}(2009)$ & Brazil & TS & $200 I-2003$ & $\mathrm{HA}$ & II.2 million & I.7/day & $\geq 40$ yrs & A.B.C.E.F \\
\hline Forastiere et $\mathrm{al}^{57}$ (2008) & Italy & CC & 1997-2004 & Mortality & 0.32 million & 19.6/day & $\geq 35$ yrs & A.B.C.E.I.H.G. \\
\hline Ko et $\mathrm{a}^{58}(2007)$ & Hong Kong & TS & 2000-2004 & $\mathrm{HA}$ & 7 million & 65.3/day & All & A.B.C.D.E \\
\hline Zanobetti et a ${ }^{59}(2000)$ & USA & TS & $1986-1994$ & $\mathrm{HA}$ & I.8 million & $22 /$ day & $\geq 65$ yrs & A.B \\
\hline Morgan et al ${ }^{60}(1998)$ & Australia & TS & $1990-1994$ & $\mathrm{HA}$ & NA & $9.7 /$ day & $\geq 65 \mathrm{yrs}$ & A.B.C.D.E \\
\hline Anderson et $\mathrm{a}^{61}(1997)$ & Europe & TS & $1977-1992$ & $\mathrm{HA}$ & I8.2 million & 49.2/day & $\geq 65$ yrs & A.B.H.E \\
\hline Peel et al ${ }^{8}(2005)$ & USA & TS & $1993-2000$ & $\mathrm{HA}$ & 4.0 million & 7.4/day & All & A.B.C.G.F.D.N \\
\hline Chen et $\mathrm{al}^{62}(2003)$ & Canada & TS & $2002-2003$ & $\mathrm{HA}$ & NA & 4,409 & $\geq 65$ yrs & A.B.E.F \\
\hline Wong et $\mathrm{al}^{63}$ (2002) & Hong Kong & TS & $1995-1998$ & Mortality & 8.5 million & 6.0/day & All & A.B.C.F \\
\hline Tenias et al ${ }^{64}(2002)$ & Spain & TS & $1994-1995$ & $\mathrm{HA}$ & 0.8 million & I.8/day & $\geq 14 \mathrm{yrs}$ & A.B.C.D.F.H \\
\hline Yang et al ${ }^{10}(2004)$ & Canada & TS & $1994-1998$ & $\mathrm{HA}$ & 2.0 million & 3.3/day & $\geq 65$ yrs & A.B.G.E.O \\
\hline Qiu et $a^{165}(2012)$ & Hong Kong & TS & $2000-2005$ & $\mathrm{HA}$ & 0.7 million & $81.1 /$ day & All & A.B.C.D.E.F.H \\
\hline Stieb et al ${ }^{66}(2009)$ & Canada & TS & $1990-2000$ & $\mathrm{HA}$ & 4.0 million & 40.5/day & All & A.B.C.D.G.O \\
\hline Wong et $\mathrm{al}^{67}$ (1999) & Hong Kong & TS & $1994-1995$ & $\mathrm{HA}$ & 7.0 million & NA & All & A.B.C.D.E.F \\
\hline Schouten et al ${ }^{68}(1996)$ & the Netherlands & TS & $1977-1989$ & $\mathrm{HA}$ & 0.76 million & I.7/day & All & A.B.C.D.F \\
\hline Fusco et $\mathrm{al}^{34}(200 \mathrm{l})$ & Rome & TS & $1995-1997$ & $\mathrm{HA}$ & 3.0 million & 13.0/day & All & A.B.C.D.H \\
\hline Sauerzapf et al ${ }^{69}(2009)$ & UK & $\mathrm{CC}$ & 2006-2007 & $\mathrm{HA}$ & 0.8 million & 1,050 & $\geq 18 \mathrm{yrs}$ & A.B.H.P \\
\hline Ramon et al ${ }^{70}(2005)$ & USA & $\mathrm{CC}$ & $1986-1999$ & $\mathrm{HA}$ & NA & 578,006 & $\geq 65 \mathrm{yrs}$ & A.B.C \\
\hline Janssen et $\mathrm{al}^{71}(20 \mid 3)$ & Europe & TS & $2008-2009$ & Mortality & I6.5 million & 17.2/day & All & A.B.C.D.F.G.H \\
\hline Lin et $\mathrm{al}^{72}(2012)$ & Taiwan & TS & $2000-2009$ & $\mathrm{HA}$ & 6.0 million & 15.0/day & All & A.B.C.D.H.M \\
\hline Bateson et $\mathrm{al}^{73}(2004)$ & USA & CC & |988-199| & Mortality & 0.06 million & 16,403 & $\geq 65$ yrs & A.B.G \\
\hline Sunyer et $\mathrm{al}^{74}(200 \mathrm{I})$ & Spain & $\mathrm{CC}$ & $1985-1995$ & Mortality & NA & 2,305 & $\geq 35 \mathrm{yrs}$ & A.B.C.H \\
\hline Kan et $\mathrm{al}^{75}(2003)$ & China & $\mathrm{CC}$ & $2000-2001$ & Mortality & NA & II.0/day & All & A.B \\
\hline Braga et $\mathrm{al}^{76}(200 \mathrm{l})$ & USA & TS & $1986-1993$ & Mortality & 12.5 million & 13.2/day & All & A.B.E.G \\
\hline Schwartz et al $\mathrm{al}^{77}$ (1992) & USA & TS & $1973-1980$ & Mortality & I.7 million & $0.9 /$ day & All & A.B.C.E.O \\
\hline Fischer et $\mathrm{al}^{78}$ (2003) & the Netherlands & TS & $1986-1994$ & Mortality & I4.8 million & 15.0/day & $\geq 65$ yrs & A.B.D \\
\hline Wong et al9 (2009) & Hong Kong & TS & $1996-2000$ & Both & 8.0 million & $\begin{array}{l}\text { M 5.9/day, } \\
\text { HA } 91.5 / \text { day }\end{array}$ & All & B.H \\
\hline
\end{tabular}


Table I (Continued)

\begin{tabular}{|c|c|c|c|c|c|c|c|c|}
\hline Study (year) & Location & Design & Period & Outcome & Population & Events & Age & Confounders \\
\hline Xu et $\mathrm{al}^{9}(2000)$ & China & TS & $1992-1993$ & Mortality & 3.I million & 6.2/day & All & A.B.D \\
\hline Janssen et $\mathrm{al}^{80}$ (2002) & USA & TS & 1985-1994 & $\mathrm{HA}$ & NA & NA & $\geq 65$ yrs & A.B.C.D.G \\
\hline Dominici et $\mathrm{al}^{81}$ (2006) & USA & TS & 1999-2002 & $\mathrm{HA}$ & I I.5 million & 26.0/day & $\geq 65$ yrs & A \\
\hline Yang et $\mathrm{al}^{82}(2000)$ & USA & TS & 1990-1994 & $\mathrm{HA}$ & NA & 3,115 & All & A.B.C.D.E.F.G \\
\hline Schwartz et $\mathrm{al}^{83}$ (1994) & USA & TS & $1986-1989$ & $\mathrm{HA}$ & 0.9 million & $2.0 /$ day & $\geq 65 \mathrm{yrs}$ & A.B.G.E.F \\
\hline Schwartz(s) et al ${ }^{44}$ (I994) & USA & TS & $1986-1989$ & $\mathrm{HA}$ & 2.5 million & $3.0 /$ day & $\geq 65$ yrs & A.B.G.F \\
\hline Schwartz(t) et al ${ }^{84}$ (I994) & USA & TS & $1986-1989$ & $\mathrm{HA}$ & 4.4 million & $5.8 /$ day & All & A.B.E.G \\
\hline Sunyer et $\mathrm{al}^{85}(1993)$ & Spain & TS & $1985-1989$ & $\mathrm{HA}$ & NA & I5.8/day & $\geq 45$ yrs & A.B.C.O \\
\hline Lippmann et $\mathrm{al}^{86}$ (2000) & USA & TS & $1982-1994$ & Both & NA & $8.0 /$ day & All & A.B.E.H \\
\hline Dab et $\mathrm{al}^{87}(1996)$ & France & TS & 1987-1992 & Both & 6. 14 million & 12.0/day & All & A.B.C.D.E.H.Q \\
\hline Leitte et al ${ }^{88}$ (2009) & Romania & TS & $2001-2002$ & Both & 0.1 million & I.4/day & All & A.B.D.E.H.G.R \\
\hline Pande et al ${ }^{89}$ (2002) & India & TS & 1997-1998 & $\mathrm{HA}$ & NA & $22.0 /$ day & All & A.B.E.F \\
\hline Cirera et al ${ }^{90}(20 \mathrm{II})$ & UK & TS & $1995-1998$ & $\mathrm{HA}$ & 0.2 million & $2.0 /$ day & All & A.B.C.E.H.G \\
\hline Yang et $\mathrm{al}^{91}$ (2007) & Taiwan & $\mathrm{CC}$ & 1996-2003 & $\mathrm{HA}$ & 2.6 million & I5.9/day & All & A.B \\
\hline Lee et $\mathrm{al}^{92}(2007)$ & Taiwan & $\mathrm{CC}$ & 1996-2003 & $\mathrm{HA}$ & I.5 million & $8.6 /$ day & All & A.B \\
\hline Peacok et $\mathrm{al}^{93}(2010)$ & UK & TS & $1995-1997$ & $\mathrm{HA}$ & NA & 94 & $\geq 65$ yrs & A.B.E \\
\hline Zhang et $\mathrm{al}^{94}(2013)$ & China & TS & $2008-2011$ & $\mathrm{HA}$ & 8.7 million & 2,000 & All & A.B.F.G \\
\hline Cho et $\mathrm{al}^{95}(2013)$ & Korea & $\mathrm{CC}$ & 2005-2009 & $\mathrm{HA}$ & 4,989 & 548 & $\geq 44$ yrs & A.B.S.D \\
\hline Tian et $\mathrm{al}^{96}(2014)$ & Hong Kong & TS & $200 I-2007$ & $\mathrm{HA}$ & 8.0 million & 57.0/day & All & A.B.C.D \\
\hline To et $\mathrm{al}^{97}(2015)$ & Canada & TS & $2003-2010$ & $\mathrm{HA}$ & I 3.0 million & 615,540 & All & A.C.E.O.T \\
\hline Cai et $\mathrm{al}^{98}(2015)$ & China & TS & $2006-2008$ & $\mathrm{HA}$ & 7.0 million & 121,463 & All & A.B.E.F \\
\hline
\end{tabular}

Note: Both= the outcome includes HA and Mortality.

Abbreviations: A, temperature; B, humidity; C, day of week; CC, case-crossover study; D, holiday; $\mathrm{E}$, seasonality; $\mathrm{F}$, long-term trend; $\mathrm{G}$, barometric pressure; $\mathrm{H}$, influenza; HA, hospital admission; I, chronic time trend; J, rainfall; K, precipitation; L, overcast; M, wind velocity; N, hospital entry/exit; NA, not available; O, animal trend; P, pollen; $\mathrm{Q}$, linear effects; R, nonlinear effects, S, sunlight hours; T, socioeconomic status; TS, time-series study; yrs, years old.

North America (the USA and Canada), South America (Mexico and Brazil), Australia, and Europe; 12 citations focused on the association between short-term air pollution exposure and COPD mortality, whereas 41 focused on the COPD emergency hospitalization. The final 6 citations paid attention to both. The most frequently reported age-group was all age-group, followed by the group $>65$ years old. Table 1 shows the potentially adjusted confounders. Furthermore, Table S1 lists the components of air pollution and average concentrations. Most publications provided multiple estimates for single lags (eg, lag0, lag1, and lag2), whereas some provided cumulative or distributed lags that were adopted only in the overall analysis. The 4-score system showed that the majority was judged to be of good or intermediate quality.

\section{Overall analysis}

There was a significant association between short-term exposure and the risk of COPD exacerbations for all the gaseous and particulate pollutants (Figure 2; Table 2). Figure S1 shows the details explicitly. Table 2 presents PAFs with all the prevalence of exposure. The associations, for gaseous air pollutants, were found to be strongest at lag0 and decreased as the time increased. Conversely, the most significant associations appeared at lag3 for particulate air pollutants.

Through sensitivity analysis, after excluding studies that increased risk of bias, no difference was found in the overall effect estimates (Table S2). Publication bias was observed in pollutants of $\mathrm{SO}_{2}, \mathrm{O}_{3}$, and $\mathrm{PM}_{10}$ by using Egger's test for asymmetry $P<0.05$ (Table 2; Figure S2). After adjusting the symmetry with the trim and fill method, it was found that the effect directions of all air pollutants did not change, but it yielded the effects adjusted for funnel plot asymmetry as expected.

\section{Subgroup analyzes}

\section{Lag exposure}

Based on the lag exposure subgroup analysis, it was found that the following outcome of lag subgroup analysis for each air pollutant were consistent with the results of overall analysis (RR [95\% CI], $I^{2}$, Egger's test $\left.[P]\right)$ : lag0 for $\mathrm{SO}_{2}$ (1.007 [1.003, 1.011]; 91.5\%; $P=0.31), \mathrm{NO}_{2}$ (1.030 [1.026, 1.033]; 94.9\%; $P=0.78)$, and $\mathrm{PM}_{2.5}$ (1.002 [1.001, 1.005]; $76.8 \% ; P=0.36)$; lag1 for CO (1.000 [0.985, 1.005]; 61.4\%; $P=0.41)$; lag3 for $\mathrm{O}_{3}(1.013$ [1.010, 1.016]; 5.90\%; $P=0.35)$ and $\mathrm{PM}_{10}(1.009[1.006,1.011] ; 55.8 \% ; P=0.12)$. Figure 2 and Table S3 present more detailed results.

\section{Study quality}

This subgroup included 56 citations (20 studies fulfilling the high-quality score of 4 points and 36 studies receiving the middle quality score of 3 points). Except for $\mathrm{SO}_{2}$ and $\mathrm{O}_{3}$, all the other air pollutants revealed valid associations with COPD risk (Table S3). Among them [N, RR (95\% CI); Egger's test, $P$ ], $\mathrm{NO}_{2}$ (27 studies; 1.017 [1.015, 1.019]; $P=0.147$ ), 


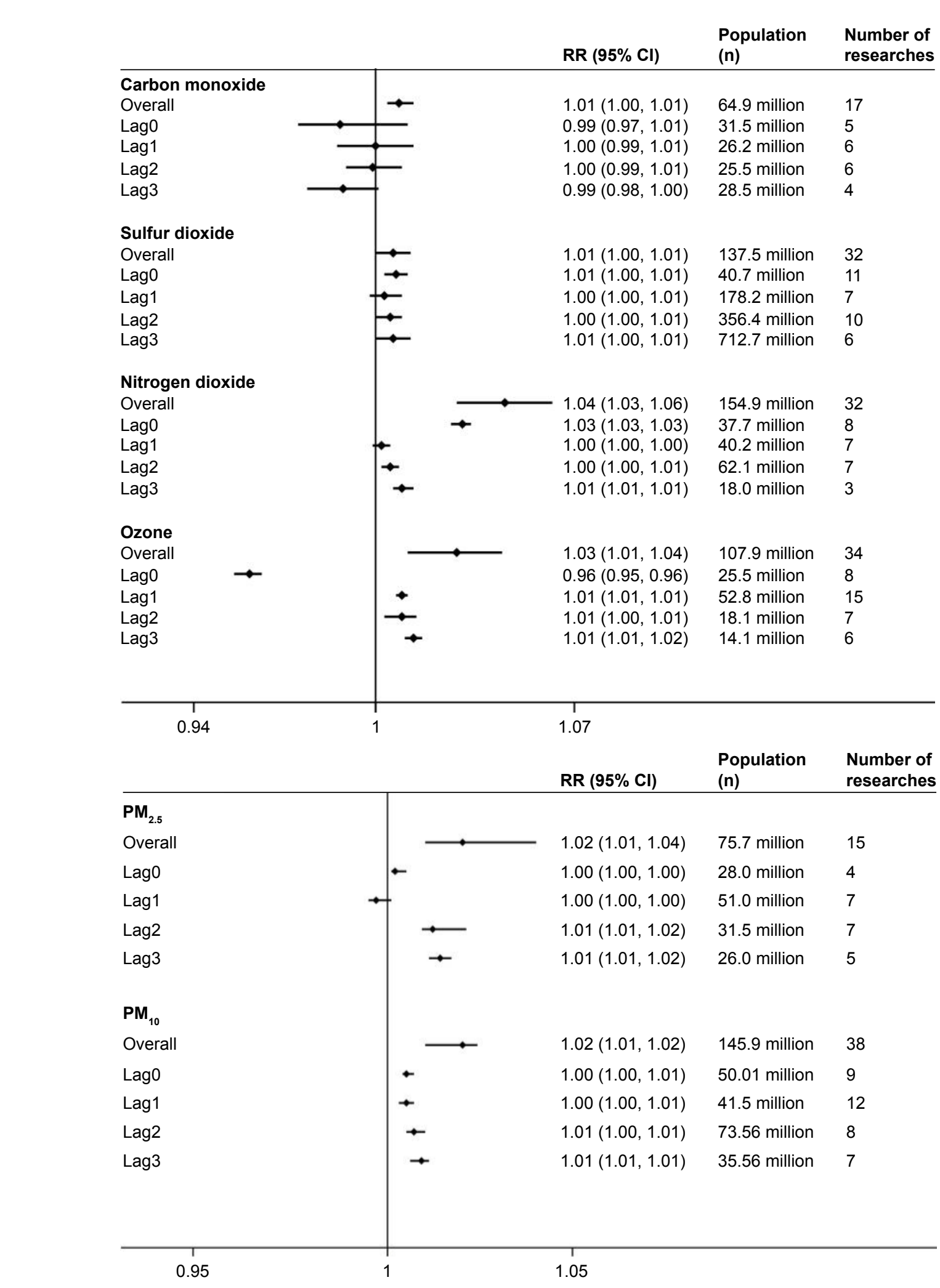

Figure 2 Associations between gaseous and particular air pollution and COPD risk stratified by time lag (days).

Abbreviations: $\mathrm{Cl}$, confidence interval; COPD, chronic obstructive pulmonary disease; RR, relative risk.

CO (13 studies; $1.006[1.002,1.011] ; P=0.163), \mathrm{PM}_{2.5}$ (15 studies; $1.001[1.000,1.001] ; P=0.187$ ), and $\mathrm{PM}_{10}$ (34 studies; 1.001 [1.000, 1.001]; $P=0.187$ ) were proved to be unfavorable associations.
Property classification

As shown in Figure 3, this analysis was conducted based on COPD exacerbation outcomes (hospitalization or mortality), geographical location (Asia or non-Asia), population 
Table 2 Subgroup analysis by gaseous and particulate pollutants

\begin{tabular}{|c|c|c|c|c|c|c|}
\hline & \multicolumn{4}{|c|}{ Gaseous pollutants } & \multicolumn{2}{|c|}{ Particulate pollutants } \\
\hline & $\begin{array}{l}\text { Carbon } \\
\text { monoxide }\end{array}$ & $\begin{array}{l}\text { Nitrogen } \\
\text { dioxide }\end{array}$ & $\begin{array}{l}\text { Sulfur } \\
\text { dioxide }\end{array}$ & Ozone & $\mathbf{P M}_{2.5}$ & $\mathbf{P M}_{10}$ \\
\hline Increment & $100 \mu g / \mathrm{m}^{3}$ & $10 \mu g / \mathrm{m}^{3}$ & $10 \mu \mathrm{g} / \mathrm{m}^{3}$ & $10 \mu g / \mathrm{m}^{3}$ & $10 \mu g / \mathrm{m}^{3}$ & $10 \mu g / \mathrm{m}^{3}$ \\
\hline Mean pollutant & 1.18 & 64.56 & 26.47 & 54.90 & 14.84 & 46.44 \\
\hline Standard deviation & 0.38 & 20.32 & 10.75 & 22.87 & 8.05 & 29.50 \\
\hline Range (minimum-maximum) & $0.40-3.04$ & $10.23-126.40$ & $9.08-59.68$ & $13.19-119.47$ & $5.20-94.59$ & $11.98-135.17$ \\
\hline Number of studies & 15 & 29 & 28 & 29 & 14 & 35 \\
\hline Number of estimates & 17 & 32 & 32 & 34 & 15 & 38 \\
\hline $\mathrm{RR}(95 \% \mathrm{Cl})$ & $\begin{array}{l}1.008 \\
(1.004,1.013)\end{array}$ & $\begin{array}{l}1.045 \\
(1.028,1.062)\end{array}$ & $\begin{array}{l}1.006 \\
(1.001,1.012)\end{array}$ & $\begin{array}{l}1.028 \\
(1.011,1.044)\end{array}$ & $\begin{array}{l}1.024 \\
(1.005,1.043)\end{array}$ & $\begin{array}{l}1.017 \\
(1.012,1.022)\end{array}$ \\
\hline Heterogeneity, $I^{2}$ & 97.0 & 98.0 & 80.8 & 98.8 & 97.1 & 86.2 \\
\hline$P$-value & $<0.001$ & $<0.001$ & $<0.001$ & $<0.001$ & $<0.001$ & $<0.001$ \\
\hline \multicolumn{7}{|l|}{ PAF, \% (95\% Cl) } \\
\hline$k=100 \%$ & $0.79(0.40,1.28)$ & $4.31(2.72,5.84)$ & $0.60(0.00,1.19)$ & NA & $2.34(0.50,4.12)$ & $1.67(1.19,2.15)$ \\
\hline$k=80 \%$ & $0.64(0.32,1.03)$ & $3.47(2.18,4.67)$ & $0.48(0.08,0.95)$ & NA & $\mathrm{I} .88(0.40,3.33)$ & $1.34(0.95,1.73)$ \\
\hline$k=20 \%$ & $0.16(0.08,0.26)$ & $0.89(0.56,1.22)$ & $0.12(0.02,0.24)$ & NA & $0.48(0.10,0.85)$ & $0.34(0.24,0.44)$ \\
\hline \multicolumn{7}{|l|}{ Publication bias } \\
\hline Egger regression test, $P$-value & 0.160 & 0.147 & 0.007 & $<0.001$ & 0.447 & $<0.001$ \\
\hline Adjusted estimates $(95 \% \mathrm{Cl})$ & $\begin{array}{l}1.002 \\
(1.001,1.003)\end{array}$ & $\begin{array}{l}1.021 \\
(1.004,1.018)\end{array}$ & $\begin{array}{l}1.004 \\
(0.998,1.011)\end{array}$ & $\begin{array}{l}0.976 \\
(0.962,0.991)\end{array}$ & $\begin{array}{l}1.006 \\
(1.004,1.008)\end{array}$ & $\begin{array}{l}1.008 \\
(1.004,1.011)\end{array}$ \\
\hline
\end{tabular}

Abbreviations: $\mathrm{Cl}$, confidence interval; $\mathrm{NA}$, not available; RR, relative risk; PAF, population attributable fraction.

age (all age or age $>65$ years), and study design (timeseries or case-crossover). When classified by geographical locations, the positive relationships were more significant in Asian countries than in the non-Asian countries for air pollutants. Similar associations were also observed in age subgroups: there was a tendency toward stronger relationships between these air pollutants and COPD. The property subgroups of case-crossover study and COPD deaths had borderline significance.

Furthermore, it was also identified that subgroup of age $>65$ years for $\mathrm{SO}_{2}$ and $\mathrm{O}_{3}$, COPD mortality subgroup for $\mathrm{NO}_{2}, \mathrm{CO}$, and $\mathrm{PM}_{2.5}$, and subgroup of non-Asia population for $\mathrm{PM}_{10}$ reduced the heterogeneities of their pooled effects compared to overall analyzes. Table $\mathrm{S} 4$ shows further details.

\section{Stratification by national income}

Among all the included studies, $20 \%$ of the publications were from low-/middle-income countries in which $\sim 60 \%$ of the population originated from the People's Republic of China. $\mathrm{SO}_{2}, \mathrm{NO}_{2}$, and $\mathrm{PM}_{10}$ were commonly measured in low-/middle-income countries, such as Mexico and Brazil. Compared with the developed countries, the $\mathrm{SO}_{2}$ and $\mathrm{NO}_{2}$ short-time exposure showed more pronounced associations with COPD acute risk in the developing countries. For them, the RRs $(95 \% \mathrm{CI})$ in low-/middle-income and high-income countries were as follows: $\mathrm{SO}_{2}, 1.012(1.001,1.023)$ and 1.005 (0.996, 1.014); and $\mathrm{NO}_{2}, 1.019(1.014,1.024)$ and 1.017 (1.015, 1.019) (Figure 4). The mean concentrations of $\mathrm{SO}_{2}$ and $\mathrm{NO}_{2}$ in low-/middle-income countries were relatively higher than those of high-income countries, which was particularly concerning for the reason that these countries have disproportionate burdens of global acute exacerbation of COPD.

\section{Heterogeneity by meta-regression}

Considering the substantial heterogeneity exhibited in the overall analysis, meta-regression analysis identified that study design of $\mathrm{NO}_{2}$ (coefficient $=-0.166 ; P=0.014$ ) and $\mathrm{O}_{3}$ (coefficient $=-0.072 ; P=0.017$ ) contributed to heterogeneities significantly (Table S4). However, heterogeneity exploration similar to subgroups of location, age, and COPD subtype showed no significant contributors.

\section{Discussion}

\section{Principal findings}

To the authors' concurrent knowledge, this was the first study to report the comprehensive association between main gaseous and particulate pollutants' short-term exposure and COPD acute risk, indicating that improving air quality could reduce the risk of sudden onset of COPD and the burden of COPD worldwide. The present study found a significant association between short-term exposure to major air pollutants and COPD emergency risk, especially for $\mathrm{O}_{3}$ and $\mathrm{NO}_{2}$. Subgroup analysis showed lower heterogeneities and yielded similar associations in the overall analysis. The pooled estimates stratified by financial levels demonstrated stronger 


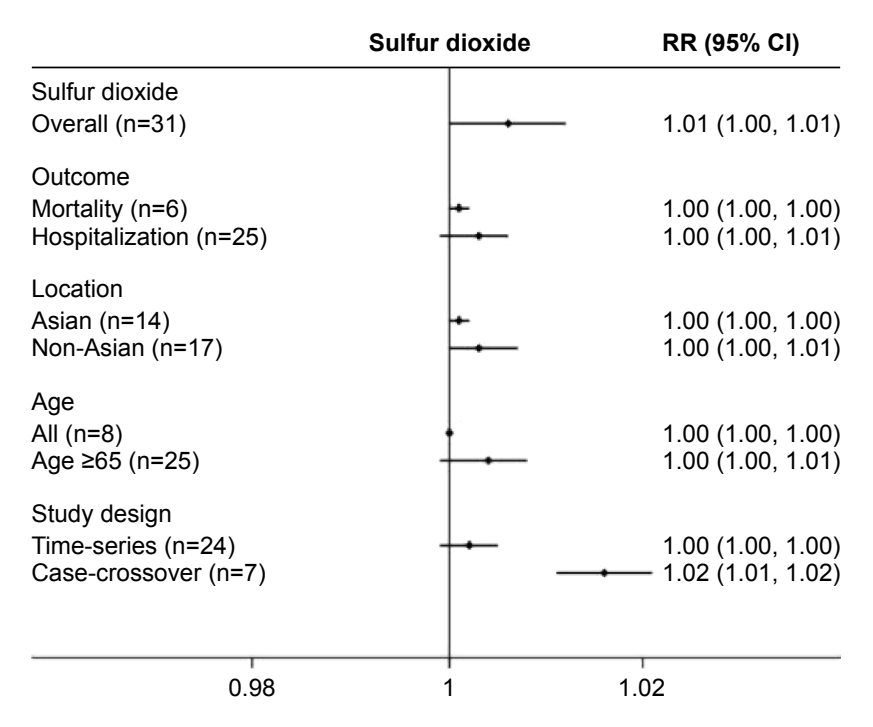

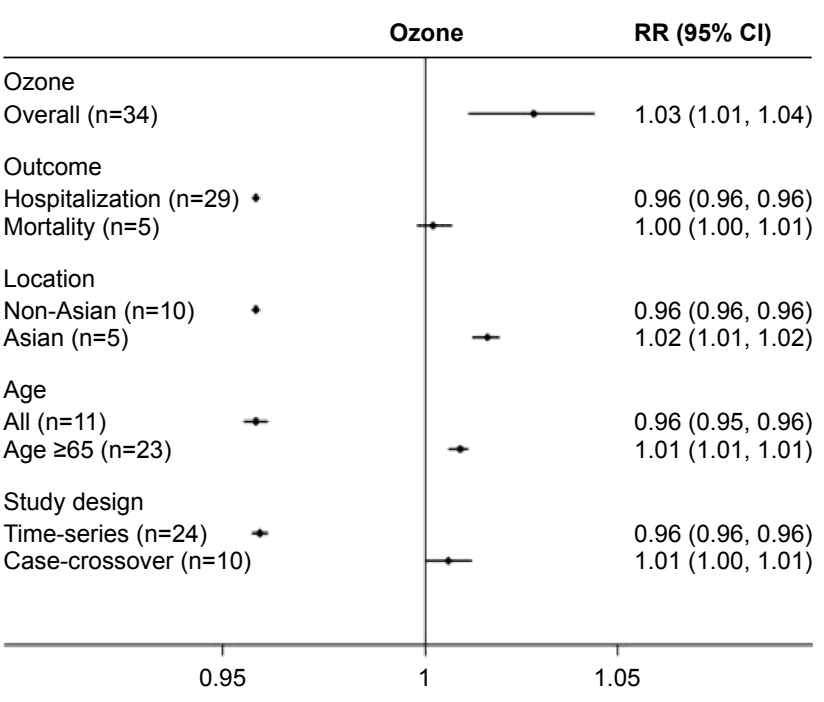

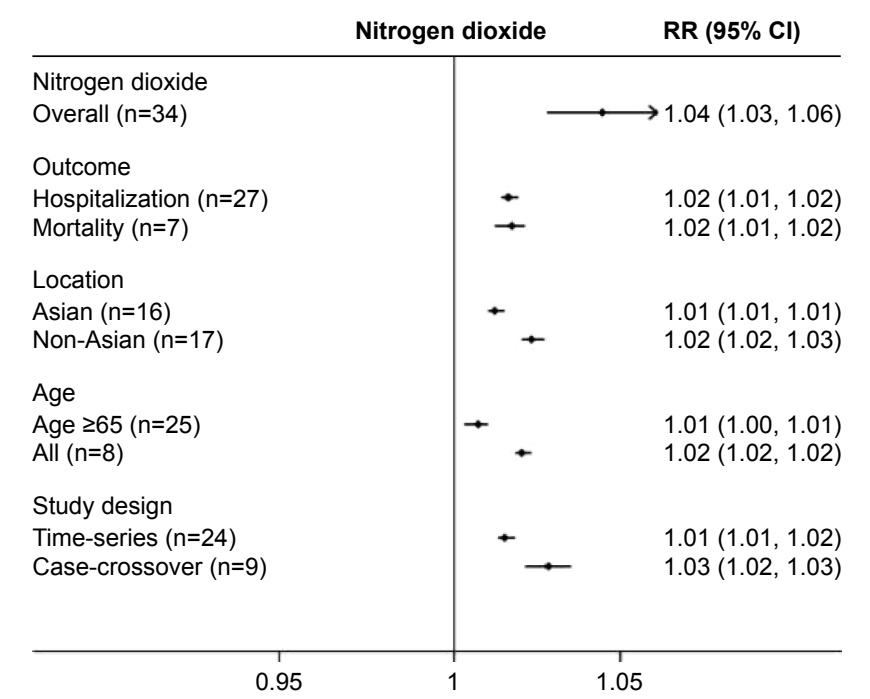

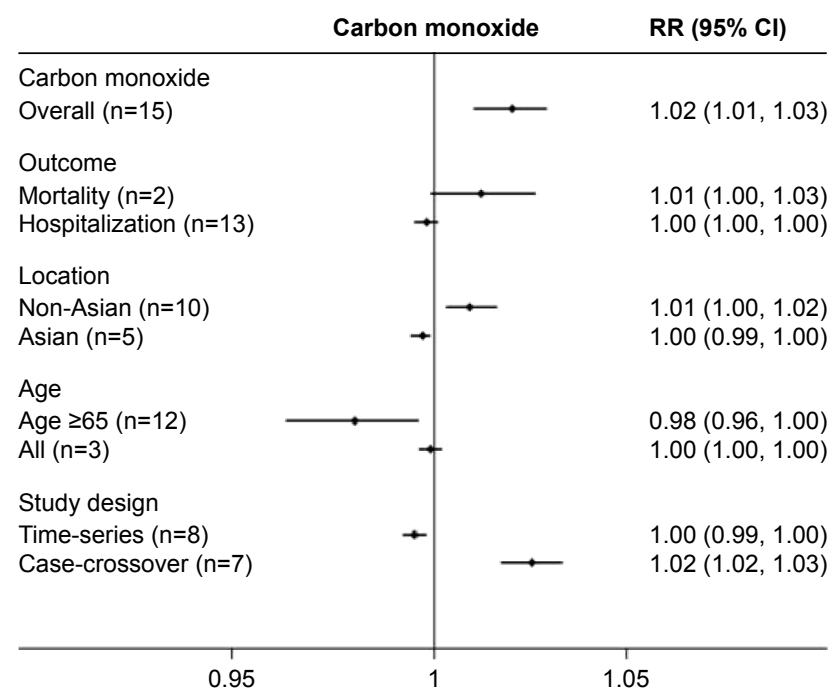

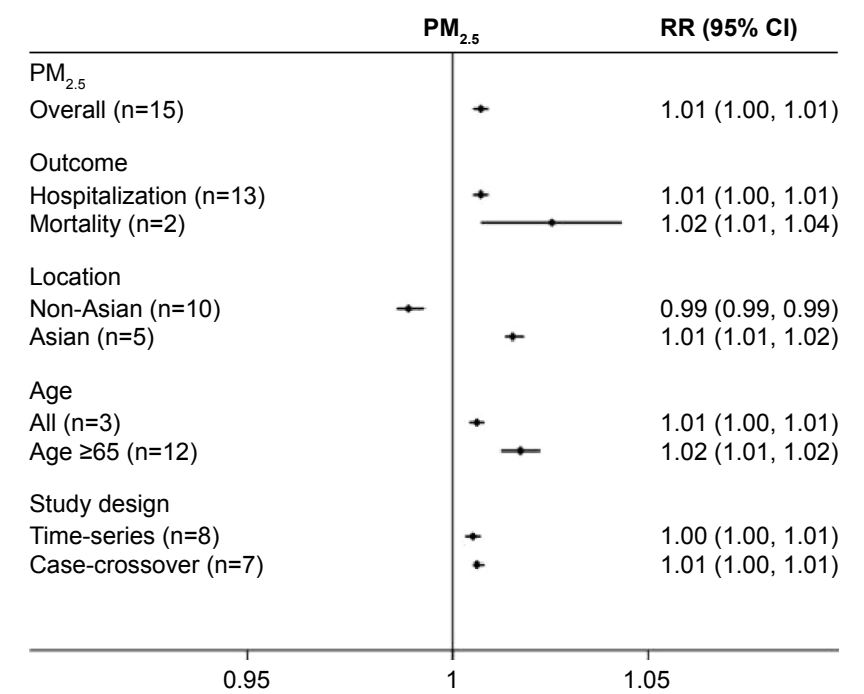

\begin{tabular}{|c|c|c|}
\hline \multicolumn{2}{|c|}{$\mathrm{PM}_{10}$} & \multirow[t]{2}{*}{$\mathrm{RR}(95 \% \mathrm{Cl})$} \\
\hline $\begin{array}{l}\mathrm{PM}_{10} \\
\text { Overall }(\mathrm{n}=38)\end{array}$ & & \\
\hline Outcome & & \\
\hline $\begin{array}{l}\text { Mortality }(n=14) \\
\text { Hospitalization }(n=124)\end{array}$ & $+\rightarrow$ & $\begin{array}{l}1.00(1.00,1.01) \\
1.01(1.01,1.01)\end{array}$ \\
\hline Location & & \\
\hline $\begin{array}{l}\text { Non-Asian }(n=13) \\
\text { Asian }(n=25)\end{array}$ & $\rightarrow$ & $\begin{array}{l}1.01(1.00,1.01) \\
1.01(1.01,1.01)\end{array}$ \\
\hline Age & & \\
\hline $\begin{array}{l}\text { Age } \geq 65(n=15) \\
\text { All }(n=26)\end{array}$ & $\leftarrow$ & $\begin{array}{l}1.00(1.00,1.01) \\
1.01(1.01,1.01)\end{array}$ \\
\hline Study design & & \\
\hline Case-crossover $(n=11)$ & $\leftarrow$ & $1.01(1.00,1.01)$ \\
\hline Time-series $(n=27)$ & $\leftarrow$ & $1.01(1.01,1.01)$ \\
\hline 0.98 & & 02 \\
\hline
\end{tabular}

Figure 3 Subgroup analysis for all gaseous and particulate air pollutants stratified by outcome, location, age, and study design. Abbreviations: $\mathrm{Cl}$, confidence interval; COPD, chronic obstructive pulmonary disease; RR, relative risk. 

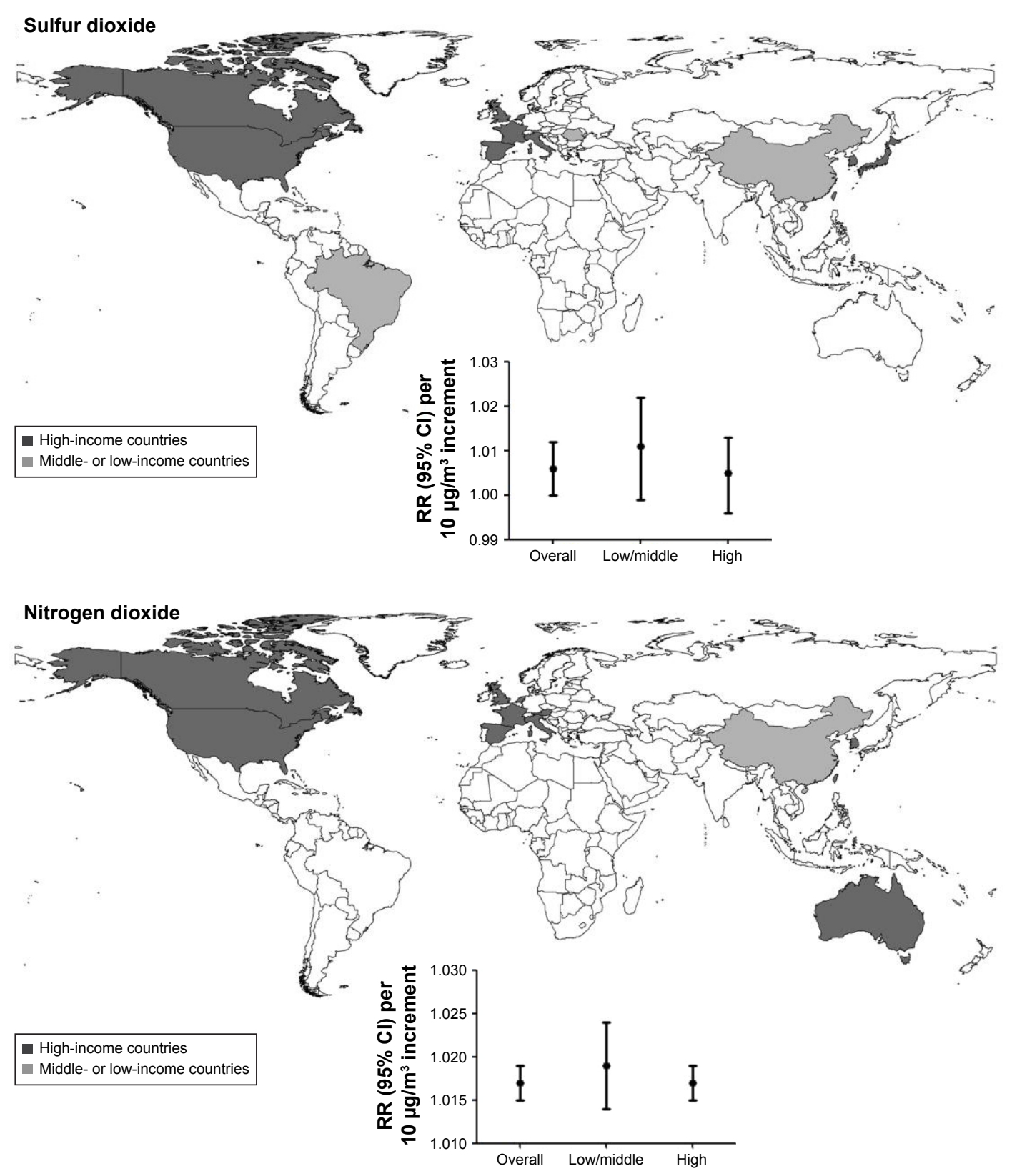

Figure 4 Cartogram identifying associations between sulfur dioxide and nitrogen dioxide short-term exposure and COPD risk stratified by countries of high- and low-I middle-income levels.

associations in low-/middle-income countries than in highincome countries.

\section{Potential mechanisms}

There were plenty of in vivo and in vitro studies to explain the plausible biomedical mechanisms for the relationship between short-term air pollution exposure and adverse outcome of COPD. ${ }^{26,27}$ One of the main mechanisms was oxidative-mediated. ${ }^{28}$ Air pollution could absorb chemical substances from the environment, which participated in the production process of reactive oxygen species. ${ }^{29}$ Oxidative stress could cause an injury in the epithelium of the airway, making the airways of COPD patients more sensitive to further damage, and impair the resistance ability of the immune system. ${ }^{2}$ Another pathogenesis mechanism is that air pollutants can cause inflammation in the lungs and can further impair the reduced pulmonary function in COPD patients. ${ }^{30}$ However, the COPD exacerbation-relevant determinants are still largely unknown. As most research studies have focused on smoking and pneumonia risk for COPD exacerbation, ${ }^{4,31,32}$ 
further studies considering the significant roles of environmental pollution are required.

\section{Interpretation}

In the present analysis, all the air pollutants showed acute disadvantageous effects on COPD patients, especially $\mathrm{NO}_{2}$ and $\mathrm{O}_{3}$. Both of these two gaseous pollutants caused an increased risk of COPD significantly (RR, 95\% CI): 1.04, $(1.03,1.06)$; and $1.03,(1.01,1.04)$. One study reported that every $10 \mu \mathrm{g} / \mathrm{m}^{3}$ increase of $\mathrm{O}_{3}$ and $\mathrm{NO}_{2}$ would result in $0.58 \%$ and $0.38 \%$ increment in the COPD risk, respectively. ${ }^{33}$ In addition, exposure to $\mathrm{SO}_{2}$ and $\mathrm{CO}$ showed weaker associations with COPD in the present study, which was consistent with a previous study. Fusco et al found that no effects were identified for $\mathrm{SO}_{2}$, and only weak associations was found for $\mathrm{CO}(2.8 \%$ increase per interquartile range (IQR), $\left.1.5 \mathrm{mg} / \mathrm{m}^{3}\right) .{ }^{34} \mathrm{NO}_{2}$ and $\mathrm{O}_{3}$ played important roles in acute respiratory attack, whereas $\mathrm{CO}$ seemed to be strongly associated with seasonality, especially in warmer seasons. In combination studies, it was difficult to separate all the estimates of $\mathrm{CO}$ by the adjustment of seasonality. ${ }^{34,35}$ For the different effects of $\mathrm{O}_{3}$ compared to other pollutants, the most important factor is the properties of $\mathrm{O}_{3}$. It is the component of photochemical reaction and shows obvious seasonality fluctuation that could affect the exacerbation rate of COPD patients. ${ }^{15}$ Moreover, it is relatively more complex to form $\mathrm{O}_{3}$ in the ambient air, depending closely on solar radiation and brightness. ${ }^{36}$ As for the adjustment of temperature, different methods adopted cause RR estimates to vary, and in the pooled analysis, it is hard to just limit the pollutants to a certain period. ${ }^{37}$

Particulate pollutants have always been considered to be responsible for the most adverse cardiovascular and respiratory diseases, and some adverse impacts induced by $\mathrm{PM}_{2.5}$ might be aggravated by $\mathrm{PM}_{10}{ }^{19}$ In the present study, particulate pollutants showed significant adverse impact on COPD patients, which further confirmed that elevated levels of particulate matters in polluted environments could promote the exacerbation of COPD. A study in New Zealand reported an $3.37 \%$ increase for each $14.8 \mathrm{mcg} / \mathrm{m}^{3}$ increase in $\mathrm{PM}_{10}$, and an Australian study also showed a 4\% increase in admissions for every $10 \mu \mathrm{g} / \mathrm{m}^{3}$ increase of $\mathrm{PM}_{10}{ }^{38} \mathrm{How}-$ ever, there were still limited studies about $\mathrm{PM}_{10}$ in developing countries. In an Asian time-series study, per $10 \mu \mathrm{g} / \mathrm{m}^{3}$ increase in $\mathrm{PM}_{10}$ indicated an $0.36 \%$ increase in respiratory mortality. ${ }^{39}$ Because of a disproportional burden of COPD exacerbation in these middle-/lower-income counties, more studies on $\mathrm{PM}_{10}$ are required to explore the combined effects of particulate pollutants.
The heterogeneities of the air pollutants $\mathrm{CO}, \mathrm{NO}_{2}$, and $\mathrm{O}_{3}$ were more significant than that of $\mathrm{SO}_{2}$. For particulate pollutants, the heterogeneity of $\mathrm{PM}_{2.5}$ was greater than that of $\mathrm{PM}_{10}$. Subgroup analysis indicated that lag exposure and age $>65$ years contributed heterogeneities more significantly. In individual studies, they measured daily variations of each pollutant in limited areas for the time period from 0 to 7 days and adjusted different kinds of confounders. ${ }^{27}$ Therefore, lag exposure for them would be a source of heterogeneity. Subgroup of mortality and age $>65$ years were also the origins for heterogeneity because COPD showed signs between the ages of 35 and 40 years primarily and it then developed very fast after 65 years. Once exposed to risk factors, COPD patients would exacerbate quickly, and mortality rate increased. ${ }^{40} \mathrm{~A}$ high quality study with higher score tends to have the higher methodological quality. ${ }^{41}$

The current analysis also indicated that the association between $\mathrm{SO}_{2}$ and $\mathrm{NO}_{2}$ short-term exposure and COPD acute risk seemed to be more pronounced in low-/middle-income countries than in high-income countries, and only $20 \%$ of the included studies were from low-/middle-income countries, and more than half of them originated from the People's Republic of China (Figure 4). This finding was of great importance because urban cities in some developing countries were in a rapid industrialization process and under the threat of severe environmental problems. ${ }^{42}$ Moreover, data from these countries were scarce, resulting from a lack of cohesive air quality policies, inadequate environmental monitoring, and a paucity of disease surveillance data. ${ }^{19}$ More monitoring information is in great demand for developing countries in order to investigate the health impacts of air pollutants. Considering the severe air pollution and disproportionate burden of COPD acute risk in the developing countries, this highlighted issue needs more attention.

\section{Practical implications}

The findings of the present study have provided evidence for the association between short-term air pollution exposure and the risk of COPD exacerbations. This called for improvement and implementation of regulations on the air quality that will provide measurable benefits to public health. More policies should be implemented to reduce major air pollutants, such as adoption the absorbers of noxious gases before release, utilization of environmentally-friendly fuels, and adoption of advanced technologies. ${ }^{43}$ Our results urge future research studies on the relationship between concentration of air pollutants and the risk estimation and also for more cooperative actions to issue alerts to high-risk populations in order to facilitate substantial public health benefits. 


\section{Limitations}

It was acknowledged that several limitations should be considered. First, the lag selection in methodologies was controversial. Exclusion of any lag from lag0 to lag7 might miss considerable information for pooled analysis. In this analysis, all the methodologies used had been reviewed. Therefore, the "priori lag" method was chosen based on the most commonly used approach. Besides, there were still potential sources of bias in the present study: the estimates included were from each publication, and whether multiple hospitalizations might occur for the same patients was not identified. Moreover, the concentration-response relationships are really fundamental references in air quality standards, but lack of details to construct the dose-response functions may limit the ability for setting criteria. Finally, for the air pollutants under the single-pollutant model, underlying interactive effects might exist. ${ }^{44}$ There was no clearly stated selection of models in combined analysis, and most of the parameters preferred the idea that multiple models for air pollutions in meta-analysis were still imperfect; ${ }^{45}$ therefore, the single-air pollutant model was used in the present study for estimations.

\section{Conclusion}

This systematic review and meta-analysis confirmed that short-term exposure to major air pollutants could significantly increase the risk for COPD exacerbations. Environmental and public health policies that can decrease the concentrations of air pollution might reduce the exacerbation burden of COPD.

\section{Acknowledgment}

This work was supported by the National Natural Science Foundation of China (41272180).

\section{Disclosure}

The authors report no conflicts of interest in this work.

\section{References}

1. Berend N. Contribution of air pollution to COPD and small airway dysfunction. Respirology. 2016;21(2):237-244.

2. Li XY, Gilmour PS, Donaldson K, MacNee W. Free radical activity and pro-inflammatory effects of particulate air pollution (PM10) in vivo and in vitro. Thorax. 1996;51:1216-1222.

3. Lopez-Campos JL, Tan W, Soriano JB. Global burden of COPD. Respirology. 2016;21(1):14-23.

4. Garcia-Aymerich J, Monsó E, Marrades RM, et al. Risk factors for hospitalization for a chronic obstructive pulmonary disease exacerbation. Am J Respir Crit Care Med. 2001;164:1002-1007.

5. Hawkins NM, Virani S, Ceconi C. Heart failure and chronic obstructive pulmonary disease: the challenges facing physicians and health services. Eur Heart J. 2013;34(36):2795-2803.
6. Lindenauer PK, Pekow P, Gao S, Crawford AS, Gutierrez B, Benjamin EM. Quality of care for patients hospitalized for acute exacerbations of chronic obstructive pulmonary disease. Ann Intern Med. 2006;144:894-903.

7. Neuberger M, Rabczenko D, Moshammer H. Extended effects of air pollution on cardiopulmonary mortality in Vienna. Atmos Environ. 2007; 41(38):8549-8556.

8. Peel JL, Tolbert PE, Klein M, et al. Ambient air pollution and respiratory emergency department visits. Epidemiology. 2005;16(2):164-174.

9. Xu Z, Yu D, Jing L, Xu X. Air pollution and daily mortality in Shenyang, China. Arch Environ Health. 2000;55(2):115-120.

10. Yang Q, Chen Y, Krewski D, Burnett RT, Shi Y, McGrail KM. Effect of short-term exposure to low levels of gaseous pollutants on chronic obstructive pulmonary disease hospitalizations. Environ Res. 2005; 99(1):99-105.

11. Atkinson RW, Carey IM, Kent AJ, van Staa TP, Anderson HR, Cook DG. Long-term exposure to outdoor air pollution and the incidence of chronic obstructive pulmonary disease in a national English cohort. Occup Environ Med. 2015;72(1):42-48.

12. Peters A, Wichmann HE, Tuch T, Heinrich J, Heyder J. Respiratory effects are associated with the number of ultrafine particles. Am J Respir Crit Care Med. 1997;155(4):1376-1383.

13. Moher D, Liberati A, Tetzlaff J, Altman DG. Preferred reporting items for systematic reviews and meta-analyses: the PRISMA statement. BMJ. 2009;339:b2535.

14. Stroup DF, Berlin JA, Morton SC, et al. Meta-analysis of observational studies in epidemiology: a proposal for reporting. Meta-analysis of Observational Studies in Epidemiology (MOOSE) group. JAMA. 2000; 283(15):2008-2012.

15. Mustafic H, Jabre $\mathrm{P}$, Caussin $\mathrm{C}$, et al. Main air pollutants and myocardial infarction: a systematic review and meta-analysis. JAMA. 2012; 307(7):713-721.

16. Savovic J, Weeks L, Sterne JA, et al. Evaluation of the Cochrane Collaboration's tool for assessing the risk of bias in randomized trials: focus groups, online survey, proposed recommendations and their implementation. Syst Rev. 2014;3:37.

17. Yang WS, Wang X, Deng Q, Fan WY, Wang WY. An evidence-based appraisal of global association between air pollution and risk of stroke. Int J Cardiol. 2014;175(2):307-313.

18. Poloniecki JD, Atkinson RW, de Leon AP, Anderson HR. Daily time series for cardiovascular hospital admissions and previous day's air pollution in London, UK. Occup Environ Med. 1997;54(8):535-540.

19. Shah AS, Langrish JP, Nair H, et al. Global association of air pollution and heart failure: a systematic review and meta-analysis. Lancet. 2013;382(9897):1039-1048.

20. Kan H, Jia J, Chen B. Acute stroke mortality and air pollution: new evidence from Shanghai, China. J Occup Health. 2003;45(5):321-323.

21. Mantel N, Haenszel W. Statistical aspects of the analysis of data from retrospective studies of disease. J Natl Cancer Inst. 1959;22: 719-748.

22. Huang Q, Li J, Sun Y, Wang R, Cheng X, Chen H. Efficacy of EGFR tyrosine kinase inhibitors in the adjuvant treatment for operable non-smallcell lung cancer by a meta-analysis. Chest. 2015;149(6):1384-1392.

23. Li J, Huang Q, Zeng F, et al. The prognostic value of global DNA hypomethylation in cancer: a meta-analysis. PLoS One. 2014;9(9):e106290.

24. Atkinson R, Kang S, Anderson H, Mills I, Walton H. Epidemiological time series studies of PM2.5 and daily mortality and hospital admissions: a systematic review and meta-analysis. Thorax. 2014;69(7):660-665.

25. Barnett AG, Williams GM, Schwartz J, et al. The effects of air pollution on hospitalizations for cardiovascular disease in elderly people in Australian and New Zealand cities. Environ Health Perspect. 2006; 114(7):1018-1023.

26. Garshick E. Effects of short- and long-term exposures to ambient air pollution on COPD. Eur Respir J. 2014;44(3):558-561.

27. Sunyer J. Urban air pollution and chronic obstructive pulmonary disease: a review. Eur Respir J. 2001;17:1024-1033.

28. MacNee W, Donaldson K. Exacerbations of COPD. Chest. 2000;117(5): 390S-397S. 
29. Kasemo B, Lausmaa J. Material-tissue interfaces: the role of surface properties and processes. Environ Health Perspect. 1994;102(Suppl 5): 41-45.

30. Abbey DE, Burchette RJ, Knutsen SF, McDonnell WF, Lebowitz MD, Enright PL. Long-term particulate and other air pollutants and lung function in nonsmokers. Am J Respir Crit Care Med. 1998;158(1): 289-298.

31. Kessler R, Faller M, Fourgaut G, Mennecier B, Weitzenblum E. Predictive factors of hospitalization for acute exacerbation in a series of 64 patients with chronic obstructive pulmonary disease. Am J Respir Crit Care Med. 1999;159(8):158-164.

32. Anthonisen NR. Smoking, lung function and mortality. Thorax. 2000; 55:729-730.

33. Ghozikali MG, Mosaferi M, Safari GH, Jaafari J. Effect of exposure to $\mathrm{O}(3), \mathrm{NO}(2)$, and $\mathrm{SO}(2)$ on chronic obstructive pulmonary disease hospitalizations in Tabriz, Iran. Environ Sci Pollut Res Int. 2015;22(4): 2817-2823.

34. Fusco D, Forastiere F, Michelozzi P, et al. Air pollution and hospital admissions for respiratory conditions in Rome, Italy. Eur Respir J. 2001; 17:1143-1150.

35. Pitard A, Viel JF. Some methods to address collinearity among pollutants in epidemiological time series. Stat Med. 1997;16(5): $527-544$.

36. Chardon B, Host S, Lefranc A, Millard F, Gremy I. What exposure indicator should be used to study the short-term respiratory health effect of photochemical air pollution? A case study in the Paris metropolitan area. Environnement, Risques \& Santé. 2007;6(5):345-353.

37. Eilstein D, Quenel P, Hedelin G, Kleinpeter J, Arveiler D, Schaffer P. [Air pollution and myocardial infarction. Strasbourg France, 1984-1989]. Rev Epidemiol Sante Publique. 2001;49(1):13-25. French.

38. Meszaros D, Markos J, FitzGerald DG, Walters EH, Wood-Baker R. An observational study of PM10 and hospital admissions for acute exacerbations of chronic respiratory disease in Tasmania, Australia 1992-2002. BMJ Open Respir Res. 2015;2(1):e00063.

39. Atkinson RW, Cohen A, Mehta S, Anderson HR. Systematic review and meta-analysis of epidemiological time-series studies on outdoor air pollution and health in Asia. Air Qual Atmos Health. 2011;5(4): 383-391.

40. Pavord ID, Jones PW, Burgel PR, Rabe KF. Exacerbations of COPD. Int J Chron Obstruct Pulmon Dis. 2016;11:21-30.

41. Sterne JAC, Egger M, Smit GD. Investigating and dealing with publication and other biases in meta-analysis. BMJ. 2001;323:101-105.

42. Kan H, Chen B, Hong C. Health impact of outdoor air pollution in China: current knowledge and future research needs. Environ Health Perspect. 2009;117(5):A187.

43. Zhang JJ, Smith KR. Household air pollution from coal and biomass fuels in China: measurements, health impacts, and interventions. Environ Health Perspect. 2007;115(6):848-855.

44. Schwartz J, Morris R. Air pollution and hospital admissions for cardiovascular disease in Detroit, Michigan. Am J Epidemiol. 1995;142(1): 23-35.

45. Gasparrini A, Armstrong B. Reducing and meta-analysing estimates from distributed lag non-linear models. BMC Med Res Methodol. 2013;13:1

46. Kloog I, Nordio F, Zanobetti A, Coull BA, Koutrakis P, Schwartz JD. Short term effects of particle exposure on hospital admissions in the MidAtlantic states: a population estimate. PloS One. 2014;9(2):e88578.

47. Meng X, Wang C, Cao D, Wong C-M, Kan H. Short-term effect of ambient air pollution on COPD mortality in four Chinese cities. Atmospheric Environment. 2013;77:149-154.

48. Tellez-Rojo M, Romieu I, Ruiz-Velasco S, Lezana M, HernandezAvila M. Daily respiratory mortality and PM10 pollution in Mexico City: importance of considering place of death. European Respiratory Journal. 2000;16(3):391-396.

49. Wordley J, Walters S, Ayres JG. Short term variations in hospital admissions and mortality and particulate air pollution. Occupational and Environmental Medicine. 1997;54(2):108-116.
50. Yorifuji T, Suzuki E, Kashima S. Hourly differences in air pollution and risk of respiratory disease in the elderly: a time-stratified case-crossover study. Environmental Health. 2014;13(1):67.

51. Schikowski T, Adam M, Marcon A, et al. Association of ambient air pollution with the prevalence and incidence of COPD. Eur Respir J. 2014;44(3):614-626.

52. Tao Y, Mi S, Zhou S, Wang S, Xie X. Air pollution and hospital admissions for respiratory diseases in Lanzhou, China. Environmental Pollution. 2014;185:196-201

53. Moolgavkar SH, Luebeck EG, Anderson EL. Air pollution and hospital admissions for respiratory causes in Minneapolis-St. Paul and Birmingham. Epidemiology. 1997:364-370.

54. Hinwood A, De Klerk N, Rodriguez C, et al. The relationship between changes in daily air pollution and hospitalizations in Perth, Australia 1992-1998: a case-crossover study. International Journal of Environmental Health Research. 2006;16(1):27-46.

55. Milutinovic S, Nikic D, Stosic L, Stankovic A, Bogdanovic D. Shortterm association between air pollution and emergency room admissions for chronic obstructive pulmonary disease in Nis, Serbia. Central European Journal of Public Health. 2009;17(1):8.

56. Arbex MA, de Souza Conceição GM, Cendon SP, et al. Urban air pollution and chronic obstructive pulmonary disease-related emergency department visits. Journal of Epidemiology and Community Health. 2009;63(10):777-783.

57. Forastiere F, Stafoggia M, Berti G, et al. Particulate matter and daily mortality: a case-crossover analysis of individual effect modifiers. Epidemiology. 2008;19(4):571-580.

58. Ko FW, Tam W, Wong TW, et al. Temporal relationship between air pollutants and hospital admissions for chronic obstructive pulmonary disease in Hong Kong. Thorax. 2007;62(9):780-785.

59. Zanobetti A, Schwartz J, Dockery DW. Airborne particles are a risk factor for hospital admissions for heart and lung disease. Environmental Health Perspectives. 2000;108(11):1071.

60. Morgan G, Corbett S, Wlodarczyk J. Air pollution and hospital admissions in Sydney, Australia, 1990 to 1994. American Journal of Public Health. 1998;88(12):1761-1766.

61. Anderson H, Spix C, Medina S, et al. Air pollution and daily admissions for chronic obstructive pulmonary disease in 6 European cities: results from the APHEA project. European Respiratory Journal. 1997;10(5):1064-1071.

62. Chen Y, Yang Q, Krewski D, Shi Y, Burnett RT, McGrail K. Influence of relatively low level of particulate air pollution on hospitalization for COPD in elderly people. Inhalation Toxicology. 2004;16(1): 21-25.

63. Wong T, Tam W, Yu T, Wong A. Associations between daily mortalities from respiratory and cardiovascular diseases and air pollution in Hong Kong, China. Occupational and Environmental Medicine. 2002;59(1):30-35.

64. Tenias JM, Ballester F, Perez-Hoyos S, Rivera ML. Air pollution and hospital emergency room admissions for chronic obstructive pulmonary disease in Valencia, Spain. Archives of Environmental Health. 2002;57(1):41-47.

65. Qiu H, Yu IT-s, Tian L, et al. Effects of coarse particulate matter on emergency hospital admissions for respiratory diseases: a timeseries analysis in Hong Kong. Environmental Health Perspectives. 2012;120(4):572.

66. Stieb DM, Szyszkowicz M, Rowe BH, Leech JA. Air pollution and emergency department visits for cardiac and respiratory conditions: a multicity time-series analysis. Environ Health. 2009;8(25):10.1186.

67. Wong TW, Lau TS, Yu TS, et al. Air pollution and hospital admissions for respiratory and cardiovascular diseases in Hong Kong. Occupational and Environmental Medicine. 1999;56(10):679-683.

68. Schouten J, Vonk J, De Graaf A. Short term effects of air pollution on emergency hospital admissions for respiratory disease: results of the APHEA project in two major cities in The Netherlands, 1977-89. Journal of Epidemiology and Community Health. 1996;50(Suppl 1): s22-s29. 
69. Sauerzapf V, Jones AP, Cross J. Environmental factors and hospitalisation for chronic obstructive pulmonary disease in a rural county of England. Journal of Epidemiology and Community Health. 2009;63(4):324-328.

70. Medina-Ramon M, Zanobetti A, Schwartz J. The effect of ozone and PM10 on hospital admissions for pneumonia and chronic obstructive pulmonary disease: A national multicity study. American Journal of Epidemiology. 2006;163(6):579-588.

71. Janssen N, Fischer P, Marra M, Ameling C, Cassee F. Short-term effects of PM 2.5, PM 10 and PM 2.5-10 on daily mortality in the Netherlands. Science of the Total Environment. 2013;463:20-26.

72. Lin Y, Chang S, Lin C, Chen Y, Wang Y. Comparing ozone metrics on associations with outpatient visits for respiratory diseases in Taipei Metropolitan area. Environmental Pollution. 2013;177:177-184.

73. Bateson TF, Schwartz J. Who is sensitive to the effects of particulate air pollution on mortality? A case-crossover analysis of effect modifiers. Epidemiology. 2004;15(2):143-149.

74. Sunyer J, Schwartz J, Tobias A, Macfarlane D, Garcia J, Anto JM. Patients with chronic obstructive pulmonary disease are at increased risk of death associated with urban particle air pollution: A case-crossover analysis. American Journal of Epidemiology. 2000;151(1):50-56.

75. Kan H, Chen B. Air Pollution and Daily Mortality in Shanghai: A Time-Series Study. Archives of Environmental Health. 2003;58(6): 360-367

76. Braga ALF, Zanobetti A, Schwartz J. The lag structure between particulate air pollution and respiratory and cardiovascular deaths in 10 US cities. Journal of Occupational and Environmental Medicine. 2001;43(11):927-933.

77. Schwartz J, Dockery DW. Increased mortality in Philadelphia associated with daily air pollution concentrations. American Review of Respiratory Disease. 1992;145(3):600-604.

78. Fischer P, Hoek G, Brunekreef B, Verhoeff A, Van Wijnen J. Air pollution and mortality in the Netherlands: are the elderly more at risk? European Respiratory Journal. 2003;21(40 supp1):34s-38s.

79. Wong PM, Lees AN, Louw J, et al. Emphysema in young adult survivors of moderate-to-severe bronchopulmonary dysplasia. European Respiratory Journal. 2008;32(2):321-328.

80. Janssen NAH, Schwartz J, Zanobetti A, Suh HH. Air conditioning and source-specific particles as modifiers of the effect of PM10 on hospital admissions for heart and lung disease. Environmental Health Perspectives. 2002;110(1):43-49.

81. Dominici F, Peng RD, Bell ML, et al. Fine particulate air pollution and hospital admission for cardiovascular and respiratory diseases. JAMA. 2006;295(10):1127-1134.

82. Yang CY, Chen CJ. Air pollution and hospital admissions for chronic obstructive pulmonary disease in a subtropical city: Taipei, Taiwan. Journal of Toxicology and Environmental Health Part A: Current Issues. 2007;70(14):1214-1219.

83. Schwartz J. PM10, ozone, and hospital admissions for the elderly in Minneapolis-St. Paul, Minnesota. Archives of Environmental Health. 1994;49(5):366-374
84. Schwartz J. Air pollution and hospital admissions for the elderly in Birmingham, Alabama. American Journal of Epidemiology. 1994;139(6):589-598.

85. Sunyer J, Saez M, Murillo C, Castellsague J, Martinez F, Anto JM. Air pollution and emergency room admissions for chronic obstructive pulmonary disease: A 5-year study. American Journal of Epidemiology. 1993;137(7):701-705

86. Lippmann M, Ito K, Nadas A, Burnett R. Association of particulate matter components with daily mortality and morbidity in urban populations. Research Report (Health Effects Institute). 2000(95):5-72, discussion 73-82.

87. Dab W, Medina S, Quenel P, et al. Short term respiratory health effects of ambient air pollution: results of the APHEA project in Paris. Journal of Epidemiology and Community Health. 1996;50(Suppl 1):s42-s46.

88. Leitte AM, Petrescu C, Franck U, et al. Respiratory health, effects of ambient air pollution and its modification by air humidity in Drobeta-Turnu Severin, Romania. Science of the Total Environment. 2009;407(13):4004-4011.

89. Pande J, Bhatta N, Biswas D, et al. Outdoor air pollution and emergency room visits at a hospital in Delhi. Indian Journal of Chest Diseases and Allied Sciences. 2002;44(1):13-20.

90. Cirera L, García-Marcos L, Giménez J, et al. Daily effects of air pollutants and pollen types on asthma and COPD hospital emergency visits in the industrial and Mediterranean Spanish city of Cartagena. Allergologia et Immunopathologia. 2012;40(4):231-237.

91. Yang C-Y, Chen C-J. Air pollution and hospital admissions for chronic obstructive pulmonary disease in a subtropical city: Taipei, Taiwan. Journal of Toxicology and Environmental Health, Part A. 2007;70(14):1214-1219.

92. Lee I-M, Tsai S-S, Chang C-C, Ho C-K, Yang C-Y. Air pollution and hospital admissions for chronic obstructive pulmonary disease in a tropical city: Kaohsiung, Taiwan. Inhalation Toxicology. 2007;19(5):393-398.

93. Peacock JL, Anderson HR, Bremner SA, et al. Outdoor air pollution and respiratory health in patients with COPD. Thorax. 2011:thx. 2010.155358.

94. Zhang Z, Wang J, Chen L, et al. Impact of haze and air pollution-related hazards on hospital admissions in Guangzhou, China. Environmental Science and Pollution Research. 2014;21(6):4236-4244.

95. Cho J, Choi YJ, Suh M, et al. Air pollution as a risk factor for depressive episode in patients with cardiovascular disease, diabetes mellitus, or asthma. Journal of Affective Disorders. 2014;157:45-51.

96. Tian L, Ho KF, Wang T, et al. Ambient carbon monoxide and the risk of hospitalization due to chronic obstructive pulmonary disease. American Journal of Epidemiology. 1159;180(12):1159-1167.

97. To T, Feldman L, Simatovic J, et al. Health risk of air pollution on people living with major chronic diseases: a Canadian population-based study. BMJ Open. 2015;5(9):e009075.

98. Cai J, Chen R, Wang W, Xu X, Ha S, Kan H. Does ambient CO have protective effect for COPD patient? Environ Res. 2015;136:21-26.
International Journal of COPD

\section{Publish your work in this journal}

The International Journal of COPD is an international, peer-reviewed journal of therapeutics and pharmacology focusing on concise rapid reporting of clinical studies and reviews in COPD. Special focus is given to the pathophysiological processes underlying the disease, intervention programs, patient focused education, and self management protocols.

\section{Dovepress}

This journal is indexed on PubMed Central, MedLine and CAS. The manuscript management system is completely online and includes a very quick and fair peer-review system, which is all easy to use. Visit http://www.dovepress.com/testimonials.php to read real quotes from published authors. 